\title{
Equine ocular mast cell tumor: histopathological and immunohistochemical description
}

\author{
Ana R. FLORES ${ }^{1}$, Ana AZINHAGA ${ }^{2}$, Elisabete PAIS ${ }^{2}$, Fátima FARIA ${ }^{1}$, Francisco NUNES ${ }^{3}$, \\ Fátima GARTNER ${ }^{1,4,5 *}$ and Irina AMORIM ${ }^{1,4,5}$ \\ ${ }^{1}$ Department of Pathology and Molecular Immunology of the Institute of Biomedical Sciences Abel Salazar (ICBAS), \\ University of Porto, 4050-313 Porto, Portugal \\ ${ }^{2}$ Vetplus Veterinary Clinic Lda, 3200-532 Tomar, Portugal \\ ${ }^{3}$ Vasco da Gama University School (EUVG), 3020-210 Coimbra, Portugal \\ ${ }^{4}$ Institute for Research and Innovation in Health (i3S), University of Porto, 4200-135 Porto, Portugal \\ ${ }^{5}$ Institute of Molecular Pathology and Immunology of the University of Porto (IPATIMUP), 4200-465 Porto, Portugal
}

This report describes an ocular mast cell tumor in a 13-year-old female sport horse. Clinical examination revealed a solitary firm mass located in the ocular mucosa, protruding from behind the left lower eyelid. The lesion was surgically removed and submitted to histopathology. Microscopically, the mass was composed of sheets of well-differentiated neoplastic round cells circumscribed by delicate connective tissue. Positive Giemsa and J. Equine Sci.
Vol. 28, No. 4 pp. 149-152, 2017 Toluidine Blue staining confirmed the presence of cytoplasmic granules. Neoplastic cells showed strong membranous and mild diffuse cytoplasmic immunoreactivity for c-KIT and a low KI-67 proliferative index. Based on these findings, a diagnosis of ocular mast cell tumor was made. Six months after surgical removal, no evidence of ocular lesion recurrence was detected.

Key words: diagnosis, eye, equine, mast cell tumor

A 13-year-old brown sport Portuguese crossbred mare, weighing $500 \mathrm{~kg}$, was presented for clinical examination with a history of a rapidly progressive ocular mass, which apparently developed after an ocular trauma. Clinical examination revealed a firm reddish mass protruding from behind the left lower eyelid that measured $2.0 \mathrm{~cm}$ in diameter and contained hard yellow-grey punctuations on the surface. The differential diagnosis included ocular neoplasia, abscess, conjunctivitis, and parasitic or eosinophilic granuloma. Antibiotic therapy was implemented, and two weeks later, the mass was found to have decreased in size at a follow-up appointment; however, it did not disappear. One month after the first evaluation, the owner declined further diagnostics and clinical care and requested surgical excision of the mass. The lesion was surgically removed, fixed in $10 \%$

Received: April 4, 2017

Accepted: August 18, 2017

*Corresponding author. e-mail: fgartner@ipatimup.pt

(C)2017 Japanese Society of Equine Science

This is an open-access article distributed under the terms of the Creative Commons Attribution Non-Commercial No Derivatives (by-nc-nd) License. (CC-BY-NC-ND 4.0: https://creativecommons.org/licenses/ by-nc-nd/4.0/) buffered formalin, embedded in paraffin, and sent for histopathologic examination. Consecutive serial $2 \mu \mathrm{m}$-sections were processed for routine staining (H\&E), histochemistry (Giemsa and toluidine blue) and immunohistochemistry.

Several morphological features were evaluated by H\&E staining, as previously reported [17].

For immunohistochemistry, sections were deparaffinized and hydrated, and antigen retrieval was performed in a water bath in $10 \%$ antigen retrieval solution $(\mathrm{pH} \mathrm{6.0)}$ ) for $25 \mathrm{~min}$. Slides were cooled for $10 \mathrm{~min}$ at room temperature and rinsed twice in triphosphate buffered saline (TBS) for 5 min. The Novolink ${ }^{\mathrm{TM}}$ Max-Polymer Detection System (Novocastra, Newcastle, U.K.) was used for visualization, according to the manufacturer's instructions. Slides were then incubated for two hours, at room temperature, with polyclonal rabbit anti-human c-KIT (Dako, diluted 1:450) and nuclear antigen KI-67 (clone MIB-1, Dako, diluted 1:50). These specific antisera had already been successfully used in equine tissues $[2,5,17]$. Sections were rinsed twice with TBS in each step of the procedure. Color was developed with 3,3'-diamino-benzidine (DAB; Sigma, St. Louis, MO, U.S.A.), and sections were then counterstained with hematoxylin, dehydrated and mounted. For negative 

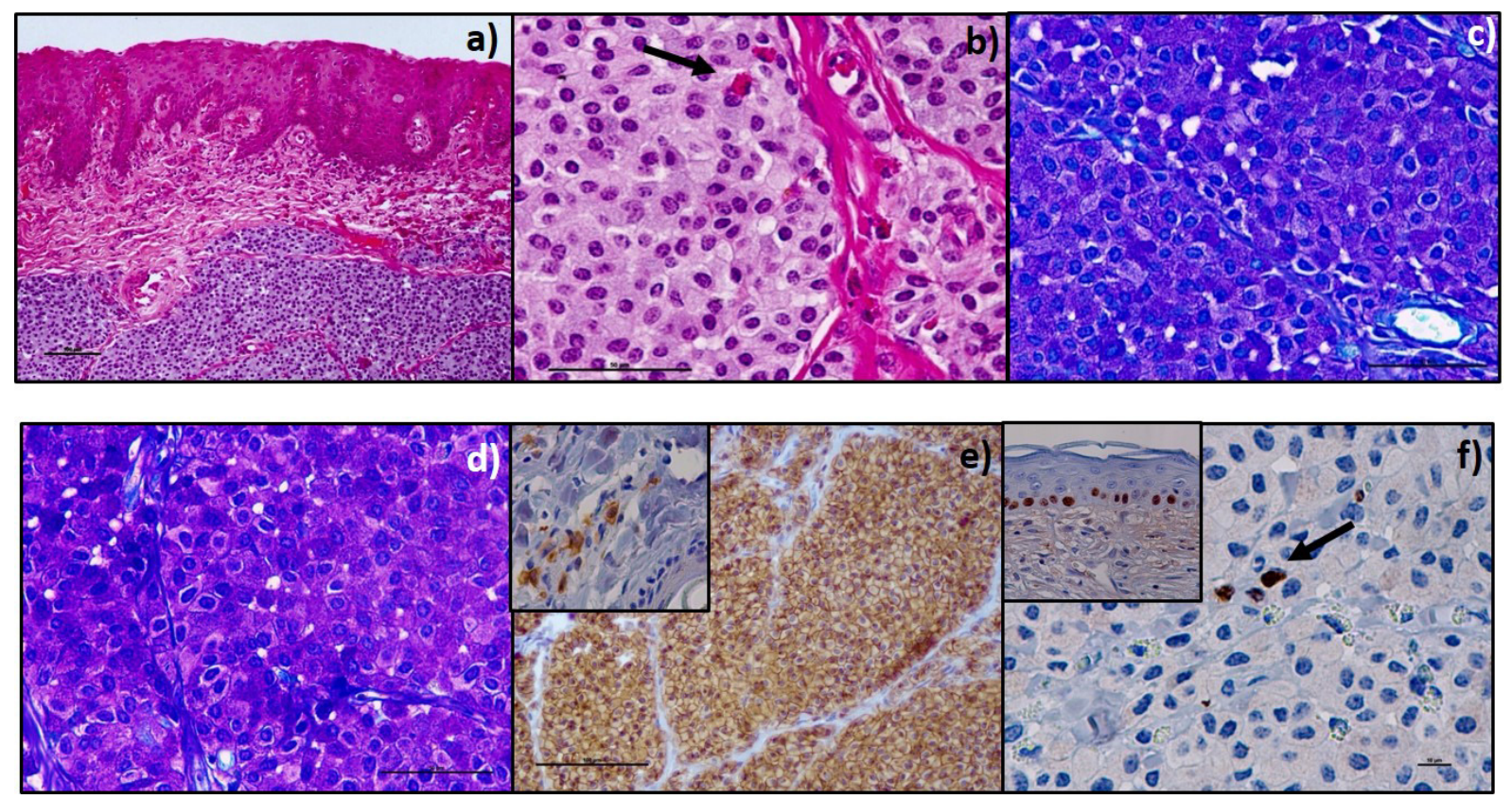

Fig. 1. (a) Histological section from the equine ocular MCT composed of sheets of round cells circumscribed by thin trabeculae of connective tissue. H\&E, 100×. (b) The neoplastic mast cells have central nuclei and faint intracytoplasmic granules and are accompanied by a few eosinophils (arrow). H\&E, 400×. (c, d) Note the intracytoplasmic granules present in the neoplastic cells highlighted with Giemsa and toluidine blue staining, respectively. 400×. (e) Strong membranous and mild diffuse cytoplasmic immunopositivity in of almost all neoplastic cells for c-KIT. The inset shows the c-KIT-positive control. IHC, 200×. (f) Tumor cells showing minimal nuclear immunoexpression of KI-67 (arrow). The inset shows the KI-67-positive control. IHC, 600× and 400×, respectively.

controls, the primary antibody was replaced with another of the same immunoglobulin isotype. Sections of normal equine skin were used as positive controls.

The immunoexpression of C-KIT in the neoplastic mast cells was evaluated based on its subcellular location and intensity. Thus, three different KIT staining patterns were considered: (a) pattern I, expression mainly on the cell membrane with only minimal cytoplasmic staining; (b) pattern II, focal to stippled cytoplasmic staining with decreased membranous staining; and (c) pattern III, diffuse cytoplasmic staining [9]. The KI-67 proliferative index (PI) was defined as the percentage of positive nuclei, which was determined by counting at least 1,000 nuclei in 10 highpower fields (HPFs).

Microscopically, a nodular neoplastic lesion extending into adjacent conjunctival tissues was observed. The tumor consisted of a proliferation of round cells arranged in sheets or nests circumscribed by delicate trabeculae of connective tissue and supported by a scarce extracellular matrix (Fig. 1a and 1b). Neoplastic cells were well differentiated, having central, round to oval nuclei, with one or two evident nucleoli and slightly basophilic cytoplasm with faint granules and well-defined limits (Fig. 1b). Anisocytosis was mild, and nuclear pleomorphism was absent. Intralesional eosinophilic infiltration was mild, and the mitotic activity was very low (1 figure per ten HPFs). Multifocal areas of necrosis, surrounded by macrophages, lymphocytes, a few plasma cells and cellular debris, were present. The lesion was nonencapsulated and exhibited a multifocal infiltrative behavior; however, it was completely excised. Large amounts of metachromatic cytoplasmic granules were highlighted with Giemsa and toluidine blue (TB) staining (Fig. 1c and 1d).

Neoplastic cells showed both strong membranous and mild diffuse cytoplasmic staining for c-KIT, consistent with pattern I (Fig. 1e) and a PI of 5-10\% (Fig. 1f). On the basis of the morphological, histochemical, and immunohistochemical findings, a diagnosis of ocular mast cell tumor (MCT) was made. Although some histological (well-differentiated cells and complete lesion excision) and immunohistochemical features (favorable pattern of KIT labeling and reduced PI) were suggestive of a good prognosis, other indicators (such as the presence of necrosis and areas of infiltrative growth) called into question this hypothesis. Additionally, the existing literature regarding these neoplasms at this precise location and affecting this particular animal species was scarce and did not provide relevant and consistent data concerning the clinical prog- 
nosis. Thus, the clinician was alerted of the need to surveil the animal and provide careful clinical follow-up.

Equine MCTs are a rare condition compared with in other domestic species. They are usually solitary and most frequently located in the skin, accounting for $3-7 \%$ of all equine cutaneous and mucocutaneous tumors. However, they can also arise at other sites, including the upper respiratory tract and eye [11].

Given their benign clinical and biological course, equine MCTs were initially classified as mastocytosis $[1,4]$. Males are more commonly affected, and the mean age is 7 years (range 1-18 years). There is no apparent breed predisposition, although some reports suggested that the Arabian breed is overrepresented [14].

Diagnosis of MCT can be achieved either by fine needle aspiration or surgical biopsy [11]. Histologically, equine MCTs have been described as single to multiple coalescing sheets of neoplastic mast cells surrounded by variable amounts of eosinophils [11, 14]. Neoplastic mast cells are usually well differentiated, containing numerous granules that are often not visible with H\&E stain but can be visualized with TB or Giemsa stains [11]. Mitotic figures are usually rare (up to 2 figures per ten HPFs) [5]. An additional characteristic feature is the presence of multiple areas of necrosis surrounded by granulomatous inflammation [11, 14]. Mast cells release cytokines and proteolytic enzymes that result in accumulation and degranulation of eosinophils, promoting collagen degeneration and cellular necrosis with subsequent granulomatous inflammation and fibrosis [14].

Surgical excision of equine MCTs is usually curative, and it has been reported that incomplete excision or biopsy may be followed by spontaneous remission. Other effective treatments include intra- and sublesional injection of corticosteroids, cryosurgery, or radiotherapy [11].

Malignant MCTs are also rare, but there have been a few reports of apparently malignant forms in horses including a primary intraosseous lesion of the 3rd phalanx, infiltration of synovial joint structures with metastasis to local lymph nodes [11], and a cutaneous multicentric form with involvement of the thoracic and abdominal cavities [21]. Currently, there is no histological grading system capable of predicting the biological behavior of an equine MCT, as in the case of other species such as dogs [18]. Thus, the classical histological features such as high mitotic index, moderate to marked anisokaryosis, prominent nucleoli, and variable or increased $\mathrm{N}: \mathrm{C}$ ratios are used in order to make this prediction [12]. Moreover, KIT expression and proliferation markers may help to identify the equine MCTs more likely to exhibit an aggressive behavior [11, 17].

This report describes an ocular MCT in a Portuguese crossbred mare. Ocular MCTs in horses have been reported to affect the limbal area, cornea, and the third eyelid $[3,6$,
$7,13,20,22]$. Mast cells are normally found in the lamina propria of the conjunctiva, which may be the origin of this tumor in the equine eye [6]. In the present case, this origin is also the most plausible, but as similarly reported, the exact site could not be determined [6].

General morphological and histochemical features of the MCT were similar to those described above. In horses, MCT may be confused with other inflammatory conditions such as eosinophilic granuloma, onchocerciasis, or habronemiasis; however, neither of these exhibits the characteristic sheets of mast cells that are found in this neoplasm [19].

All the cases available in the literature concerning equine ocular and adnexa MCT were subjected to surgical removal $[3,6,7,13,20,22]$, and local recurrence was reported 3 months after surgery only in one case [7]. In the present case, the tumor was surgically removed by request of the owner, and six months after the intervention, a clinical examination revealed no evidences of local nor regional recurrence of the neoplastic disease.

The most useful diagnostic marker for MCT is $c-K I T$, a proto-oncogene that encodes for c-KIT receptor (KIT), a type III tyrosine kinase protein that is expressed in the cell membrane of mast cells and their progenitors $[8,10,15]$. In dogs, aberrant KIT expression has been associated with poor prognostic indicators, such as increased angiogenesis, recurrence, and decreased survival time $[9,16]$. In dogs, a correlation between the KIT immunoexpression pattern and the histological grade of MCTs has been revealed with well-differentiated tumors expressing a membranous KIT immunolabeling and with poorly differentiated tumors presenting a high cytoplasmic KIT expression [9].

Ressel et al. [17] found a correlation between cytoplasm KIT expression pattern and morphological parameters of malignancy such as lower degree of mast cell differentiation and higher proliferative activity in equine cutaneous MCT. However, this finding was not correlated with the clinical outcome or aggressive behavior. To the best of the author's knowledge, this is the first description of c-KIT immunoexpression in an equine ocular MCT. Herein, almost all neoplastic mast cells exhibited a notorious c-KIT membranous staining pattern, which suggests that this marker may also be applied in diagnosis of equine ocular MCT. Furthermore, the membranous location of c-KIT associated with the reduced proliferative index of the neoplasm along with the good clinical outcome strongly suggest a benign clinical behavior for this lesion. Nevertheless, larger and prospective studies are needed to determine the potential of proliferative index and/or c-KIT expression pattern in the prediction of the biological behavior of MCT in equine species. 


\section{References}

1. Altera, K., and Clark, L. 1970. Equine cutaneous mastocytosis. Pathol. Vet. 7: 43-55. [Medline]

2. Badial, P.E., Rashmir-Raven, A.M., Cagnini, D.Q., Oliveira-Filho, J.P., Cunha, P.H.J., Kitchell, B.E., Conceição, L.G., Mochal, C.A., and Borges, A.S. 2013. Marjolin's ulcer in two horses with hereditary equine regional dermal asthenia. J. Equine Vet. Sci. 33: 515-522. [CrossRef]

3. Bosch, G., and Klein, W.R. 2005. Superficial keratectomy and cryosurgery as therapy for limbal neoplasms in 13 horses. Vet. Ophthalmol. 8: 241-246. [Medline] [CrossRef]

4. Cheville, N.F., Prasse, K., van der Maaten, A., and Boothe, D. 1972. Generalized equine cutaneous mastocytosis. Vet. Pathol. 9: 394-407. [CrossRef]

5. Clarke, L., Simon, A., Ehrhart, E.J., Mulick, J., Charles, B., Powers, B., and Duncan, C. 2014. Histologic characteristics and KIT staining patterns of equine cutaneous mast cell tumors. Vet. Pathol. 51: 560-562. [Medline] [CrossRef]

6. Halse, S., Pizzirani, S., Parry, N.M., and Burgess, K.E. 2014. Mast cell tumor invading the cornea in a horse. Vet. Ophthalmol. 17: 221-227. [Medline] [CrossRef]

7. Hum, S., and Bowers, J.R. 1989. Ocular mastocytosis in a horse. Aust. Vet. J. 66: 32. [Medline] [CrossRef]

8. Kitamura, Y., and Hirotab, S. 2004. Kit as a human oncogenic tyrosine kinase. Cell. Mol. Life Sci. 61: 2924-2931. [Medline] [CrossRef]

9. Kiupel, M., Webster, J.D., Kaneene, J.B., Miller, R., and Yuzbasiyan-Gurkan, V. 2004. The use of KIT and tryptase expression patterns as prognostic tools for canine cutaneous mast cell tumors. Vet. Pathol. 41: 371-377. [Medline] [CrossRef]

10. London, C.A., Galli, S.J., Yuuki, T., Hu, Z.Q., Helfand, S.C., and Geissler, E.N. 1999. Spontaneous canine mast cell tumors express tandem duplications in the protooncogene c-kit. Exp. Hematol. 27: 689-697. [Medline] [CrossRef]

11. Mair, T.S., and Krudewig, C. 2008. Mast cell tumour (mastocytosis) in the horse: a review of the literature and report of 11 cases. Equine Vet. Educ. 20: 177-182. [CrossRef]
12. Malikides, N., Reppas, G., Hodgson, J.L., and Hodgson, D.R. 1996. Mast cell tumors in the horse: four case reports. Equine Pract. 18: 12-17.

13. Martin, C.L., and Leipold, H.W. 1972. Mastocytoma of the globe in a horse. J. Am. Anim. Hosp. Assoc. 8: 32-34.

14. McEntee, M.F. 1991. Equine cutaneous mastocytoma: morphology, biological behaviour and evolution of the lesion. J. Comp. Pathol. 104: 171-178. [Medline] [CrossRef]

15. Passantino, L., Passantino, G., Cianciotta, A., Ribaud, M.R., Lo Presti, G., Ranieri, G., and Perillo, A. 2008. Expression of proto-oncogene C-kit and correlation with morphological evaluations in canine cutaneous mast cell tumors. Immunopharmacol. Immunotoxicol. 30: 609-621. [Medline] [CrossRef]

16. Patruno, R., Marech, I., Zizzo, N., Ammendola, M., Nardulli, P., Gadaleta, C., Introna, M., Capriuolo, G., Rubini, R.A., Ribatti, D., Gadaleta, C.D., and Ranieri, G. 2014. c-Kit expression, angiogenesis, and grading in canine mast cell tumour: a unique model to study c-Kit driven human malignancies. BioMed Res. Int. 2014: 730246. [Medline] [CrossRef]

17. Ressel, L., Ward, S., and Kipar, A. 2015. Equine cutaneous mast cell tumours exhibited variable differentiation, proliferation activity and KIT expression. J. Comp. Pathol. 153: 236-243. [Medline] [CrossRef]

18. Scott, D.W., and Miller, W.H. 2003. Equine Dermatology, 2nd ed., W.B. Saunders, St. Louis.

19. Scott, D.W., Yager, J.A., and Wilcock, B.P. 1993. The skin and appendages. pp. 531-738. In: Pathology of Domestic Animals, 4th ed. (Jubb, K.V.F., Kennedy, P.C., Palmer, N., eds.), Academic Press, San Diego.

20. Shaiderman-Torban, A., Tatz, A., Oreff, G., Brenner, O., Dahan, R., Ofri, R., and Kelmer, G. 2016. Mast cell tumour in the third eyelid of a mare. Equine Vet. Educ. doi: 10.1111/eve.12557: 1-5.

21. Tan, R.H., Crisman, M.V., Clark, S.P., Gagea, M., and Zimmerman, K. 2007. Multicentric mastocytoma in a horse. J. Vet. Intern. Med. 21: 340-343. [Medline] [CrossRef]

22. Ward, D.A., Lakritz, J., and Bauer, R.W. 1993. Scleral mastocytosis in a horse. Equine Vet. J. 25: 79-80. [Medline] [CrossRef] 